\title{
Ciência de Mulheres Negras: um experimento de insubmissão
}

\author{
Black Women Science: an experiment of insubmission
}

Giovana Xavier ${ }^{\mathbf{1}}$

DOI: $10.1590 / 0103-11042021 E 104$

RESUMO O objetivo deste artigo foi apresentar a 'Ciência de Mulheres Negras', teoria de conhecimento feminista negro desenvolvida à luz das minhas experiências como ativista pública, historiadora e professora universitária e como coordenadora do Grupo de Estudos e Pesquisas Intelectuais Negras UFRJ. Para tal, o texto foi organizado em três partes. Na primeira, dedico-me a caracterizar a 'Ciência de Mulheres Negras' como uma epistemologia alternativa focada nos saberes de mulheres negras. Na segunda, baseada em situações de sala de aula, apresento algumas práticas curriculares focalizadas no pensamento feminista negro. Entendidas como 'atos de insubmissão', tais práticas contribuem para criar conhecimentos ligados à intelectualidade de mulheres negras e à história do Brasil. Concluo dimensionando os desafios postos ao trabalho de produção e validação de conhecimentos feministas negros na comunidade científica.

PALAVRAS-CHAVE Educação. Feminismo. Grupo com ancestrais do continente africano.

\begin{abstract}
The aim of this paper is to present the 'Black Women Science', a theory of black feminist knowledge developed in the light of experiences as a public activist, historian, and professor and as coordinator of the Black Female Intellectual Studies and Research Group UFRJ. The text was organized in three parts, in the first I dedicate myself to characterize the 'Black Women Science' as an alternative epistemology focused on the knowledge of black women. In the second, based on classroom situations, I present some curricular practices focused on black feminist thinking. Understood as 'acts of insubmission', these practices contribute to creating new knowledge linked to the intellectuality of black women and the history of Brazil. I conclude by assessing the challenges posed to the work of producing and validating black feminist knowledge in the scientific community.
\end{abstract}

KEYWORDS Education. Feminism. African continental ancestry group.

1 Universidade Federal do Rio de Janeiro (UFRJ),

Faculdade de Educação (FE) - Rio de Janeiro (RJ), Brasil.

gixavier@yahoo.com.br 


\section{Estilhaço}

Nossa fala estilhaça a máscara do silêncio. Conceição Evaristo

Foi com essa frase que, em 2017, a escritora Conceição Evaristo respondeu à pergunta "Devemos desistir de publicar nossos escritos?", da filósofa Djamila Ribeiro'. Três anos depois, em um contexto de pandemia racial global Covid-19, que já matou mais de cem mil pessoas no Brasil - a maioria negras -, as metáforas da máscara e do estilhaço evocadas pela autora, em diálogo com Grada Kilomba ${ }^{2}$, são providenciais para discutir como mulheres negras têm lutado contra a asfixia de suas vidas e ideias.

Recentemente, em mesa comemorativa do centenário da Universidade Federal do Rio de Janeiro (UFRJ), lembrei da história emblemática de Carolina Maria de Jesus; grande intérprete do Brasil, que, ao ousar praticar a autonomia intelectual com sua escrita autêntica e desconcertante, morreu de asma, sufocada pelo esquecimento punitivo da mídia, do mercado editorial e do mundo acadêmico ${ }^{3}$. Um esquecimento que conecta seu trajeto ao de intelectuais negras como Virgínia Leone Bicudo, primeira psicanalista licenciada no país; Beatriz Nascimento historiadora, que inovou ao interpretar os quilombos como sistema de organização política negra no Brasil; Azoilda Loretto da Trindade, grande pedagoga e psicóloga, autora, ao lado de Janete Santos Ribeiro, de projetos inovadores em reeducação das relações raciais na educação básica. 'Zó', como era carinhosamente chamada e com quem tive a honra de conviver como amiga e mentora, resumia de forma precisa a questão em uma afirmação recorrente em seu trabalho intelectual: 'a invisibilidade é a morte em vida’4.

Se, por um lado, essas biografias de protagonistas da história do Brasil permanecem desconhecidas da maior parte das pessoas, confirmando o silêncio e a desumanização como opressões estruturantes da vida de mulheres negras; por outro, seus legados inspiram-me a iluminar a intelectualidade desse grupo, praticando uma ciência que parte do nosso reconhecimento como agentes de conhecimento no discurso científico, em que, tradicionalmente, ocupamos o lugar de objeto. Uma missão que se situa mais na luta por ampliação de espaço institucional para uma agenda acadêmica feminista negra do que na disputa de narrativas com a academia tradicional.

Essa missão, vivenciada em várias etapas que envolvem a formação em história social, a atuação docente na licenciatura em história e pedagogia, a emergência do ativismo intelectual, o credenciamento na pós-graduação, articuladas às experiências de maternidade e espiritualidade, culminou em uma virada historiográfica em minha carreira. De historiadora social da escravidão e do pós-abolição à teórica feminista negra. Um lugar no qual tenho aprimorado uma epistemologia que traz nova personagem: a cientista negra, como aquela quem define conceitos, problemas e métodos que partem da sua avaliação como pesquisadora e de suas apostas sobre como visibilizar e contribuir com os interesses de seu grupo. Trata-se assim de uma ciência de mulheres negras, resultante de pesquisas fundamentadas em articulações e adequações de ferramentas da história social e do pensamento feminista negro dos quais derivam conhecimentos alternativos ao racismo e ao patriarcado, dentro e fora do meio acadêmico.

Focada nas subjetividades, nas experiências cotidianas e nas relações de aproximação entre sujeito e tema, essa epistemologia alternativa possibilita avançar no trabalho de 'restituição de humanidades negadas'5, iluminando as formas pelas quais mulheres negras estilhaçam as máscaras do silêncio. Produtoras de autodefinições ousadas e criativas de escrita, participação política, trabalho, família, a observação de seu trabalho intelectual é primordial para produzir novas interpretações do Brasil. Neste texto, dando continuidade ao aprimoramento de abordagens em história intelectual das mulheres negras e do método da narrativa na primeira pessoa ${ }^{6}$, organizo as ideias em três partes, calcadas na perspectiva da margem 
como espaço de liberdade e criatividade para produção acadêmica ${ }^{7}$.

Na primeira, caracterizo a referida Ciência de Mulheres Negras, destacando conceitos e métodos por meio de exemplos ligados a um fazer científico fundamentado no ponto de vista feminista negro. Na segunda, discuto questões relacionadas com o desafio de trabalhar com epistemologias feministas negras baseada em experiências com as turmas dos Cursos Intelectuais Negras e Educação, Gênero e Estudos Pós-Coloniais, oferecidos, respectivamente, na graduação e no Programa de Pós-Graduação em Educação da UFRJ. Com esse recorte, trago exemplos de novas práticas curriculares que se referem ao trabalho de 'invenção de uma comunidade científica'8. Fundamentada em demandas de conhecimento novas, como o direito à escrita na primeira pessoa, ao uso de novas linguagens e referenciais no discurso acadêmico, trazidas por estudantes das classes trabalhadoras que chegam à universidade pública a partir dos anos 2000, caracterizo tais práticas como atos insubmissos que desembocam na ampliação de espaço institucional para o feminismo negro na universidade. Concluo dimensionando a importância da apropriação do terreno teórico por mulheres negras, destacando os desafios de produzir e legitimar conhecimentos feministas negros na ciência tradicional.

\section{Ciência de Mulheres Negras: narrativa na primeira pessoa e contação de histórias}

Tecida pelo diálogo com autoras afro-americanas, do sul global e afro-brasileiras de diferentes procedências - academia, movimentos sociais, sala de aula, vida pessoal -, a Ciência de Mulheres Negras é uma teoria crítica que se caracteriza pela valorização dos pontos de vista, da experiência e da articulação entre pensar e fazer de mulheres negras. Inserida nos quadros de uma epistemologia alternativa, uma de suas principais características é a aposta no diálogo, em sala de aula e redes sociais, especialmente com as juventudes negras universitárias, como elemento primordial para uma redistribuição de conhecimento em grupos subalternizados.

Uma redistribuição focada no abrir-se às visões de mundo de pessoas comuns - seus códigos, lógicas e valores por meio de diálogos que possibilitam reavaliar o papel de mulheres negras como agentes de conhecimento na história do Brasil. Um exemplo de reavaliação encontra-se no ato de reposicionar, na produção científica, a trabalhadora doméstica como uma intelectual que elabora, planeja, gere e sistematiza saberes no espaço da casa em vez de reduzi-la à imagem de controle da trabalhadora braçal ${ }^{9}$. O que é essencial em um país que apenas em 2013 regulamentou a profissão e que em 2018 contava com 3,9 milhões de mulheres negras no seu exercício ${ }^{10}$.

Pautar e refletir sobre a natureza do trabalho doméstico e suas intersecções de gênero, raça, classe nos quadros de uma história intelectual de mulheres negras na universidade pública é importante para gerar novas formas de olhar e pesquisar as desigualdades, comprometidas mais em iluminar os protagonismos possíveis do que em denunciar os impactos da opressão"1. Isso também é importante para projetar o futuro de jovens das classes trabalhadoras em formação acadêmica, muitas das quais diaristas ou filhas de domésticas, que, com treinamento baseado em ferramentas do feminismo negro, passam a reavaliar seu papel e de suas familiares como sujeitas da própria história.

Quando vista e 'contada de baixo', a história das empregadas domésticas gera novas interpretações relativas à inteligência e à criatividade de quem queima o bolo para ter o que levar para casa e alimentar os filhos, prolonga o tempo de limpeza das bibliotecas para ficar mais perto dos livros ou que economiza e empresta dinheiro a juros para a patroa falida ${ }^{12}$. A observação dessas políticas do cotidiano de mulheres negras impulsiona-me a 
experimentar métodos de escrita como o da 'escrevivências do pós-abolição'13; por onde originam-se textos nos quais a análise historiográfica constrói-se por intermédio da articulação entre subjetividade política da autora, domínio da produção historiográfica e compromisso em evidenciar as dimensões passado-presente da história.

Na Ciência de Mulheres Negras, em vez do monólogo professoral, os conhecimentos são criados com base na escuta da professora para a turma, da turma para a professora e de todas entre si; dentro de uma 'comunidade de aprendizado'14 na qual o trabalho acadêmico dá-se via cooperação e valorização das singularidades individuais que compõem o grupo.

Os programas de curso coletivos, experimentos aprimorados no Curso Intelectuais Negras, desde 2018 são um exemplo de ciência prática e participativa. A construção de tais programas parte de um levantamento de temas e autoras feito em aula, seguido da minha avaliação como professora sobre o melhor acabamento para proposta, levando em conta o equilíbrio entre o obrigatório e as demandas de conhecimento pautadas pelas estudantes. A mediação das monitoras bolsistas, universitárias que já cursaram a disciplina, e que trazem pontos de vista específicos - afinidades com autoras, aulas favoritas, ideias de oficinas, comentários da turma -, é primordial. Por meio desse sistema, temos semestralmente novos programas, dentro de um circuito de coautoria integrado por professora, monitora e estudantes, representantes de uma nova comunidade científica, interessada no pensamento de mulheres negras.

Esse é um aspecto interessante do método porque mexe com minha subjetividade e com a maneira pela qual me relaciono com a ciência. Ao considerar a turma como uma comunidade de aprendizado, em vez de centro irradiador do saber, preciso estar aberta ao novo. Ao inusitado da sala. Praticar essa abertura em um contexto de exigências, como uma das únicas professoras negras, aumenta o peso do trabalho e as cobranças, exigindo atenção, equilíbrio.
Requer também coragem para assumir o erro e o desconhecimento como direitos, tradicionalmente negados às mulheres negras, sobretudo no contexto acadêmico. Ao dizer "Eu não sei, obrigada por me apresentarem", conheci autoras e discussões importantíssimas. Linn da Quebrada, Stela do Patrocínio, Tatiana Nascimento. Mulherismo Africana, Nutricídio, Slam das Minas. Intelectuais Negras levadas para universidade por jovens negras das classes trabalhadoras.

A valorização da riqueza de detalhes das histórias pessoais, observando minuciosamente que elementos se repetem ou se diferenciam nas narrativas, também integra a metodologia. O trabalho intelectual de ouvir e articular o que ouço à minha própria história abriu novas portas para compreensão do pensar de mulheres negras. Portas nas quais a cozinha e o quintal passam a ser examinados como espaços de produção de suas políticas do cotidiano ${ }^{15}$. Conta a estudante de comunicação social que atravessa diariamente o Rio de Janeiro, saindo de São João de Meriti para ter aulas na Urca, no campus da Praia Vermelha:

Fui visitar minha avó. Entrei pelo quintal. Meu avô me deu um abraço, entregando-me uma caixa. Quando abri, estava cheia de fotos de família. Eu estava em muitas e nunca tinha me visto daquele jeito. Naquele dia fui apresentada a mim mesma.

Quando ouvimos as histórias das nossas avós, bisas, tias, primas, irmãs mais velhas ou mesmo as nossas, contadas ou recontadas na primeira pessoa ${ }^{16}$, lançamos mão de um tradicional recurso de produção de conhecimento do pensamento feminista negro: a contação de histórias ${ }^{17}$. Não se trata de oposição ou hierarquia entre oral e escrito, mas de articulação entre o que se ouve, o que se escreve e o que se lê. Uma articulação focada nos saberes de mulheres negras e que culmina em novas formas de escrita acadêmica. 


\section{Ciência de Mulheres Negras: atos insubmissos de validação de conhecimento}

Em um esforço de sistematização, posso dizer que Ciência de Mulheres Negras é derivada de um objetivo, um pressuposto e um desafio. $\mathrm{O}$ objetivo é partir da experiência de mulheres negras como um recurso para gerar problemas, hipóteses e evidências científicas. O pressuposto - lapidado em aulas, leituras, diálogos - é a afirmação de que todas as mulheres negras são intelectuais, com múltiplos fazeres, saberes e visões de mundo. Já o desafio diz respeito à construção de caminhos para subversão do cânone científico - masculino e branco -, ampliando o espaço institucional para esse novo tipo de interpretação. Algo que exige treinamento para aprender a olhar tal cânone de dentro e de fora, mapeando as possibilidades de subvertê-lo. Os atos insubmissos praticados na sala de aula e que atravessam os muros da universidade são momentos essenciais nesse processo.

Insubmisso é o adjetivo grafado por Conceição Evaristo ${ }^{19}$ para qualificar as lágrimas de mulheres negras e no qual me inspiro para refletir sobre os processos de validação do conhecimento de intelectuais negras. Atos insubmissos pelos quais se tecem formas de visibilizar o sujeito político mulher negra na comunidade científica e os quais passo a apresentar.

\section{'Ato insubmisso' 1. Intelectual negra: com nome e sobrenome}

Um dos atos insubmissos característicos da Ciência de Mulheres Negras é a elaboração de listas de referências bibliográficas nas quais as autoras são elencadas primeiro por seus nomes próprios, rompendo a estrutura patriarcal Sobrenome + Prenome. A apresentação desse formato costuma gerar associações ao improviso, erro ou desconhecimento das normas tradicionais. Um estranhamento do qual me aproprio como mote para discutir autoria, autonomia intelectual e autorização de conhecimento e que surgiu de incômodos e reflexões acerca da contradição entre o trabalho de visibilizar o pensamento de mulheres negras nomeando-as por intermédio da lógica patriarcal. Pode parecer algo pequeno, mas não é, se considerarmos que a bibliografia é um dos principais dispositivos examinados durante $o$ processo de validação ou invalidação do conhecimento científico. Quem se lê e quem se cita (ou não) definem nossos lugares no mundo acadêmico. Logo, como se cita também tem impacto. É gratificante ir ao meu escaninho, pegar a volumosa pilha de trabalhos finais e olhar as últimas páginas, nas quais Ida Mara Freire, Miriam Alves, Núbia Regina Moreira são catalogadas a partir da premissa de Lélia Gonzales de que 'o negro tem de ter nome e sobrenome', nesta ordem ${ }^{20}$.

\section{'Ato insubmisso' 2. Intelectual negra: autora}

Também gera resultados muito positivos o investimento de elaborar e trabalhar com programas de curso compostos exclusivamente por autoras feministas negras, dados os pontos de vista e perguntas relacionados com o desafio de trabalhar com métodos feministas, escutando cuidadosamente, criticando os paradigmas tradicionais e criando alternativas. Trata-se de uma metodologia que tem contribuído para visibilizar e legitimar o pensamento de mulheres negras na ciência brasileira, por meio da seleção de autoras e referenciais exclusivos do pensamento feminista negro e da realização de atividades baseadas nas articulações entre teoria e prática, história pessoal e fazer acadêmico. O contato com estas autoras e ferramentas em aulas é uma parte essencial do processo de validação de conhecimentos, pois sua presença na sala configura-se, para muitas estudantes, em um primeiro diálogo com pensadoras que mais adiante serão parte de seus referenciais, sendo incorporadas em suas pesquisas acadêmicas. 


\section{'Ato insubmisso' 3. Intelectual negra: por contágio}

O trabalho com o conceito de escrevivência, de Conceição Evaristo, também desemboca em atos insubmissos. Apoiadas, legitimadas e livres para pensar e escrever enunciando suas identidades de gênero e raça - "minha escrita é contaminada pela minha condição de mulher negra"21(1) -, universitárias registram os conhecimentos que produzem sobre temas como organização e planejamento familiares, papel da educação, convivência intergeracional e impactos da universidade na comunidade negra por meio de suas subjetividades.

Uma estudante de belas artes emocionou a turma contando que, após apresentada a Conceição Evaristo no Curso Intelectuais Negras, passou a ler os contos da autora todas as noites para a avó. A senhora, uma chefa de família que 'lê e escreve muito pouco', tornou-se fã da escritora. Já a mãe de um estudante do curso de letras decidiu voltar a estudar depois que o filho levou para casa os debates sobre o direito de ser uma intelectual negra. A mãe, 'depois do filho criado', tornou-se estudante de serviço social.

\section{'Ato insubmisso' 4. Intelectual negra: escrita autêntica}

As oficinas de escrita autêntica conduzidas na graduação e na pós, ambas desde 2016, provêm do compromisso com uma educação focada ${ }^{22}$ nas mulheres negras e na crítica ao conservadorismo dos modelos eurocêntricos. Fundamentados na normatividade bibliográfica de autores homens, cis, europeus e norte-americanos, tais modelos, com os quais grupos subalternizados não se identificam, ilustram o que Veena Das nomeia violência do cotidiano. Aquela que internalizamos como normal.

A recusa dessa internalização levou-me à busca de alternativas de ensino e pesquisa. Fartos na literatura de feministas negras e de cor como Audre Lorde e Ochy Curiel, seus problemas, métodos e conceitos são fundamentais para o sucesso dessas oficinas e para o 3aprimoramento da Ciência de Mulheres Negras ${ }^{23}$.

Em uma das aulas da graduação, nas quais trabalhamos com Veena Das ("violência inerente ao cotidiano")24(285); e Mari Matsuda ("fazer a outra pergunta") ${ }^{25(1189)}$, a turma apresentou a demanda por espaço para trabalhar a redação acadêmica. Considerando as discussões e, também, o compromisso de visibilizar autoras negras brasileiras, realizamos uma oficina de escrita autêntica com base no já citado livro 'Insubmissas lágrimas de mulheres negras', de Conceição Evaristo. A partir da leitura e de um roteiro norteador, as estudantes foram convidadas a escrever uma narrativa na primeira pessoa na qual centrassem esforços em articular suas histórias aos conceitos trabalhados no curso.

Durante uma hora, compartilhamos, em voz alta, histórias que nos fizeram entender o que representa construir-se como intelectual negra. Famílias separadas, meninas órfãs, avós zelosas, jovens mães, sem a devida parceria dos homens. Crianças indo para escola sozinhas, abençoadas pelas rezas maternas de quem sai cedo para servir ao outro. Lágrimas de mulheres que, como disse uma estudante, "não se submeteram ao que lhes gerou a dor".

A contação da história dessa oficina, selecionada em meio a tantas histórias emocionantes que marcam minha trajetória como professora da UFRJ, demonstra a relevância de produzir novas teorias do conhecimento. Nesse cenário político de conservadorismo e ao mesmo tempo de efervescência de novos espaços públicos de debates, é necessário dar continuidade à produção de saberes autônomos, focados nos 'projetos políticos de mulheres negras' ${ }^{25}$.

\section{Ciência de Mulheres Negras: a insubmissão experimentada}

O modelo de formação eurocêntrica, baseado em aulas monólogos e nos pressupostos científicos de neutralidade e afastamento, torna a 
experiência acadêmica de um número significativo de pessoas dolorosa e traumática. Em detrimento do estímulo à autoria e à criatividade, naturaliza-se à aplicação de teorias e métodos prontos definidos por um sujeito universal, velho conhecido, levando quem não se enxerga nesse paradigma a problemas como evasão, traumas, adoecimento psíquico e mesmo à morte. Já na categoria docente, as exigências do produtivismo acadêmico, naturalizadas principalmente em programas de pós-graduação, acabam atuando como barreiras de contenção a reflexões densas e à criatividade de pesquisadoras, que, devido às pressões do produtivismo, sucumbem às metas e cronogramas opressores - e, por mais que não se comente, também adoecem. Ou melhor, adoecemos.

Com um treinamento acadêmico baseado nessa perspectiva, mas também acessando espaços de formação como movimentos sociais negros, feministas, partidários, terreiros, o meu tornar-se professora universitária veio acompanhado de muitas reflexões e dilemas sobre como manter equilíbrio, bem-estar e produzir teorias e métodos científicos baseados no diálogo com o público interno e externo à universidade. Desse modo que, como apresentado neste texto, todos os meus produtos acadêmicos partem da indagação: como validar os conhecimentos de mulheres negras no discurso científico?

Discutir questões como essas contribui para produção de novos paradigmas que levem em conta os saberes e a curiosidade relacionados com os percursos que realizamos em nossas carreiras acadêmicas. Diariamente, converso com estudantes interessadas em aprender estratégias para trabalhar com epistemologias feministas negras, sem que suas ideias sejam invalidadas, interditadas pela ciência tradicional. É muito comum, nesse processo, ouvir histórias de conflitos ideológicos em processos de orientação, reavaliação de posturas acadêmicas após o contato com o pensamento feminista negro, angústias e preocupações sobre ser uma pesquisadora branca que estuda a história de mulheres negras sem objetificar.

Focados em sujeitos antagônicos (mulher negra 'outro do outro' e homem branco 'sujeito universal'), alimentar em meu trabalho o pressuposto da intelectualidade feminina negra e assumir o desafio de subverter o cânone alinha-se à tradição feminista negra de "uso criativo da margem"26(99). Aprimorando a percepção dessa margem como lugar da inovação, estilhaça-se o pressuposto de que a produção teórica é terreno masculino, abrindo-se caminhos para um entendimento feminista negro da história.

Alternativa ao eurocentrismo, a Ciência de Mulheres Negras segue impulsionando e impulsionada. Movimentos que se dão por meio da promoção de uma educação focada na produção de currículos e programas feministas negros de educação e história do Brasil; que culminam na conversão da sala de aula em espaço seguro para compartilhamento de histórias e saberes relacionados com temas variados: família, trabalho, política, espiritualidade. Na criação de métodos feministas negros - realização de vivências lúdicas, oficinas de escrita autêntica, produção de curtas, contação de histórias.

Tudo isso faz parte de um projeto de formação de novas gerações acadêmicas em uma perspectiva de ativismo científico fundamentada nas visões de mundo de mulheres negras geradoras de um novo repertório científico que desafia e propõe uma alternativa à neutralidade e ao distanciamento como formas universais de produção de conhecimento. Ciência de Mulheres Negras é, assim, uma insubmissão experimentada construída por intermédio da aposta na ponte entre o eu e o nós, em uma comunidade científica de professora e estudantes organizada sob o signo da intelectualidade feminina negra.

\section{Agradecimentos}

Agradeço às monitoras Thais Vilalba, Nathalia Braga, hoje formadas e à época estudantes de História e Comunicação Social pelo trabalho 
altamente qualificado que desenvolveram como monitoras da disciplina Intelectuais Negras entre 2016 e 2018. Agradeço também a Nathalia Correia, estudante do curso de Pedagogia, atualmente monitora do curso.

\section{Colaboradora}

Xavier G (0000-0002-6118-3889)* é responsável pela elaboração do manuscrito.

\section{Referências}

1. Ribeiro D. Entrevista Conceição Evaristo: nossa fala estilhaça a máscara do silêncio. Carta Capital. 2017. [acesso em 2020 nov 2]. Disponível em: https://www. cartacapital.com.br/sociedade/conceicao-evaristo-201cnossa-fala-estilhaca-a-mascara-do-silencio201d.

2. Kilomba G. Memórias da plantação. São Paulo: Cobogó; 2019.

3. Xavier G. Intelectuais Negras e educação pós-pandemia: possibilidades nos dias de destruição. In: Festival do Conhecimento da Universidade Federal do Rio de Janeiro. 2020 Jul 14; Rio de Janeiro.

4. Trindade AL. Fragmentos de um discurso sobre afetividade. In: Brandão AP, Trindade AL, editoras. Saberes e fazeres: modos de ver. Cadernos A Cor da Cultura. Rio de Janeiro: Fundação Roberto Marinho; 2006. [acesso 2020 ago 26]. Disponível em: http:// www.acordacultura.org.br/sites/default/files/kit/ Cadernol_ModosDeVer.pdf.

5. Xavier G, editora. Intelectuais Negras: Visíveis. [Rio de Janeiro]: Malê; 2017.

6. Xavier G. Você pode substituir mulheres negras como objeto de estudo por mulheres negras contando a sua própria história. Rio de Janeiro: Malê; 2019.
7. hooks B. Teoria feminista negra: da margem ao centro. São Paulo: Perspectiva; 2019.

8. Xavier G. Grupo Intelectuais Negras UFRJ: a invenção de uma comunidade científica e seus desafios. Rev. Trabalho Necessário. 2021 [acesso em 2021 mar 8]; 19(38):224-239. Disponível em: https://periodicos. uff.br/trabalhonecessario/article/view/43121/28414.

9. Collins PH. Pensamento feminista negro: conhecimento, consciência e a política do empoderamento. São Paulo: Boitempo; 2019.

10. Pinheiro L, Lira F, Fontoura MRN. Os desafios do passado no trabalho doméstico do século XXI: reflexões para o caso brasileiro a partir dos dados da PNAD Contínua. Brasília, DF: IPEA: 2019. [acesso em 2020 ago 26]. Disponível em: https://www.ipea.gov. br/portal/images/stories/PDFs/TDs/td_2528.pdf.

11. Lima M, Prates I. Emprego doméstico e mudança social: reprodução e heterogeneidade na base da estrutura ocupacional brasileira. Tempo Social. 2019 [acesso em 2020 ago 26]; 31(2):150-171. Disponível em: http:// www.revistas.usp.br/ts/article/view/149291/154876.

12. Santana B. A escrita de si de mulheres negras: memória e resistência ao racismo. [tese]. São Paulo: Universidade de São Paulo; 2020. 279 p. 
13. Xavier G. Você pode substituir mulheres negras como objeto de estudo por mulheres negras contando sua própria história. Rio de Janeiro: Malê, 2019.

14. hooks B. Ensinando a transgredir: a educação como prática da liberdade. São Paulo: Martins Fontes; 2013.

15. Marshall P. From the poets in the kitcheen. New York Times. 1983. [acesso em 2020 nov 2]. Disponível em: https://www.nytimes.com/1983/01/09/books/from-the-poets-in-the-kitchen.html.

16. Xavier G. Você pode substituir mulheres negras como objeto de estudo por mulheres negras contando sua própria história. Rio de Janeiro: Malê; 2019.

17. Collins PH. Pensamento feminista nego. In: Gray D, editora. Telling Stories: Black Women Historians in the Ivory Tower. [Chapel Hill]: The University of North Carolina Press; 2008.

18. Parmar P. Feminismo negro: la política como articulación. In: Jabardo M, editora. Fe-minismos Negros: Una Antología. Madrid: Traficantes de Sueños; 2012. p. 245-267. [acesso em 2020 ago 26]. Disponível em: https://www.traficantes.net/sites/default/files/ pdfs/Feminismos\%20negros-TdS.pdf.

19. Evaristo C. Insubmissas lágrimas de mulheres negras. Belo Horizonte: Nandyala; 2011.
20. Freire IM. Tecelãs da existência. Estudos Feministas. 2014 [acesso em 2020 ago 26]; 22(2):565-584. Disponível em: https://periodicos.ufsc.br/index.php/ref/ article/view/36545.

21. Evaristo C. Insubmissas lágrimas de mulheres negras. Belo Horizonte: Nandyala; 2011.

22. Collins PH. Pensamento feminista negro: conhecimento, consciência e a política do empoderamento. São Paulo: Boitempo; 2019.

23. Lorde A. Irmã Outsider: ensaios e conferências. Belo Horizonte: Autêntica; 2019.

24. Das V. Violence, Gender and Subjectivity. Annual Review of Anthropology. 2008 [acesso em 2020 ago 26]; 37:283-299. Disponível em: https://www. annualreviews.org/doi/pdf/10.1146/annurev.anthro.36.081406.094430.

25. Davis A. Mulheres, cultura e política. São Paulo: Boitempo; 2017.

26. Collins PH. Pensamento feminista negro: conhecimento, consciência e a política do empoderamento. São Paulo: Boitempo; 2019.

\footnotetext{
Recebido em 27/08/2020

Aprovado em 20/05/2021

Conflito de interesses: inexistente
}

Suporte financeiro: não houve 